\title{
Preparation of PVDF UF Membranes under an External Electric Field with PVP as Additive
}

\author{
Jing He and Baoli Shi
}

\author{
Polymer Membrane Laboratory, College of Science, Northeast Forestry University, Harbin, Heilongjiang, \\ China
}

\begin{abstract}
In this study, PVDF UF membranes were prepared with PVP as additive via a favorable method of applying high voltage external electric field $(2 \mathrm{kV})$ through the immersion precipitation phase inversion process. The influence of external electric field on the structure, surface functional groups, membrane potential, and surface hydrophilicity of the membranes were researched. In addition, anti-fouling property and separation performance of the membranes were also investigated. The results indicated that the protein adsorption amount on the electric treated membranes was distinctly reduced. Especially for the electric treated PVDF membrane with PVP K70 as additive, the value of water contact angle reached $75.4^{\circ}$ and the protein adsorption amount decreased $76 \%$, reaching $20.39 \mu \mathrm{g}^{\circ} \mathrm{cm}^{-2}$. The separation performance of the electric treated membrane was also superior to that of the un-treated membrane. All the experimental results indicated that this electric treated approach open a promising way for the modification of PVDF membrane because it combined membrane preparation and modification in only one physical step without additional chemical reagents.
\end{abstract}

Keywords: Electric field, membrane potential, PVDF membrane, ultrafiltration, adsorption.

\section{INTRODUCTION}

The membrane bioreactor (MBR) has become a popular technology for wastewater treatment and water recycle because it offers several advantages over the conventional processes such as the produced water quality can be highly improved. The facilities of MBR can be downsized but the pollution load capacity is high and the sludge production is low [1]. PVDF membrane has been commonly used in MBR technology due to its excellent anti-fouling property, good chemical resistance, outstanding processability and mechanical properties [2,3]. However, as other polymer membranes, PVDF membrane is also faced with membrane fouling problem which can reduce permeability during water treatment [4].

In order to enhance its anti-fouling performance, various methods were exploited to modify the hydrophilicity of PVDF membranes, which were mainly classified into surface modification and blending modification. The surface modification was usually used through coating or grafting a functional layer on the prepared membrane surface. The major modified sites occurred on the top and/or bottom surface of the membrane, except the inside pores of the membrane due to the limited diffusion ability of the modifying agents into the membrane pores [5-7]. The common blending method was a convenient way to reach a desired function $[8,9]$. However, the blended quantity of

*Address correspondence to this author at the Polymer Membrane Laboratory, College of Science, Northeast Forestry University, Harbin, Heilongjiang, China; Tel: +86 4518219 2327; Fax: +86 45182192327 ;

E-mail: shi_baoli@yahoo.com the additives was usually high. In recent years, some specific amphiphilic copolymers were prepared and widely researched as blending additives. The preparation of them generally required atom transfer radical polymerization (ATRP) [10] or reversible addition-fragmentation chain transfer polymerization (RAFT) [11]. Nevertheless, both of the above modification methods needed adding other chemical reagents when preparing membranes.

In one of our previous study, an externally applied electric enhancing technique was used to modify polyethersulfone (PES) UF membrane [12]. For this method, an electric field was applied to the nascent PES membranes before the immersion precipitation phase inversion stage. The surface electric properties of the obtained membranes were just permanently changed. In comparison to the coating and grafting technologies, this method didn't need to add any other chemical reagents and it didn't change the membrane pore size, therefore avoiding the loss of membrane flux.

In this work, in order to enhance the anti-fouling property, PVDF UF membranes were prepared with PVP as additive through the above introduced electric enhancing technique via immersion precipitation phase inversion. The effects of the external electric field on the structure, surface functional groups, membrane potential, and surface hydrophilicity of the membranes were researched. In addition, anti-fouling property and separation performance of the PVDF membranes were also measured in this experiment. 


\section{EXPERIMENTAL}

\subsection{Materials}

PVDF (Solef 6010) was purchased from Solvay, Belgium. N-methyl-2-pyrrolidone (NMP, AR) was provided by Tianjin Kermel Chemical Reagents Development Centre, China. Different grades of PVP (K10, K30, K50, K70 and K90) were purchased from Shanghai Aoke Industry Co., Ltd., China. Bovine serum albumin (BSA, molecular weight $68,000 \mathrm{~g} \cdot \mathrm{mol}^{-1}$ ) was purchased from BeiJing AoBoXing Bio-tech Co., Ltd., China.

\subsection{Membrane Preparation}

First, a home-made equipment was used to form a D.C. electric field. The schematic diagram of the experimental setup is shown in Figure 1. Two stainless steel plates with $22.5 \mathrm{~cm}$ in length and $17.5 \mathrm{~cm}$ in width were used as electrodes. The top electrode (positive electrode) was fixed on the top of a box. The bottom electrode (negative electrode) was supported by a polyamide stand. The gap between the top electrode and the bottom electrode was $2.0 \mathrm{~cm}$. The voltage of the top electrode was regulated with a D.C. power which was set at $2 \mathrm{kV}$.

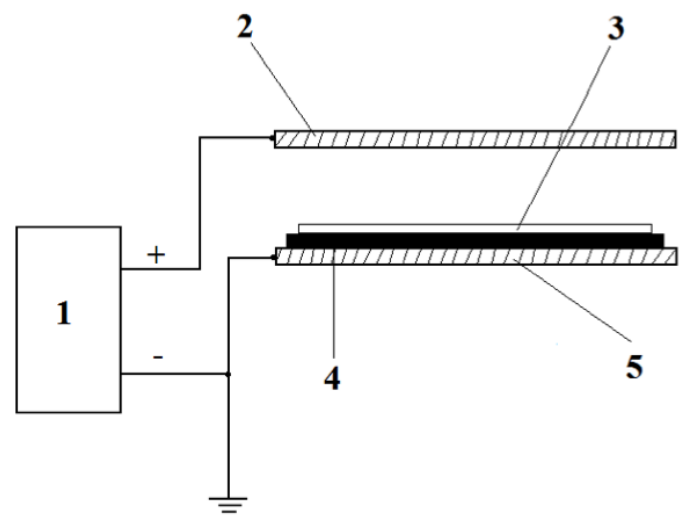

Figure 1: Schematic diagram of experimental setup for preparation of membranes. 1. D.C. power, 2. top electrode (stainless steel), 3. membrane, 4. glass plate, 5. bottom electrode (stainless steel).

The membranes were prepared by the classical immersion precipitation phase inversion method. PVDF powders were dried at $60{ }^{\circ} \mathrm{C}$ for at least $24 \mathrm{~h}$ before use. Dope solutions were prepared by blending PVDF, PVP and NMP. The concentration of PVDF and PVP in the casting dope solutions was $16 \mathrm{wt} \%$ and $5 \mathrm{wt} \%$, respectively. After complete dissolving and degassing, the homogeneous casting solutions were cast uniformly onto a glass plate by means of a hand-casting knife with a knife gap set at $350 \mu \mathrm{m}$ and then the glass plate was rapidly moved onto the bottom electrode. After 30 seconds, the glass plate was immediately immersed into a coagulation water bath at $17^{\circ} \mathrm{C}$. After peeling off from the glass plate, the membranes were rinsed with distilled water and stored in distilled water for at least $24 \mathrm{~h}$ before measurement. The thickness of each membrane was about $200 \mu \mathrm{m}$.

\subsection{Characterization of Membranes}

\subsubsection{Measurement of Hydrophilicity}

The hydrophilicity of the membranes was determined by measuring the water contact angle using a self-made contact angle instrument. Dried membranes with the size of $20 \mathrm{~mm} \times 20 \mathrm{~mm}$ were measured on this equipment with deionized water as probe. To minimize the experimental error, ten locations were randomly chosen for each membrane and then the average value was calculated.

\subsubsection{Morphology Characterization of Membranes}

The top surface and cross-section morphology of the membranes was observed with a scanning electron microscope (SEM, FEI Sirion, Holland). The samples were prepared by fracturing the membranes in liquid nitrogen. All specimens were coated with a thin layer of gold by sputtering before being viewed with the SEM.

\subsubsection{Characterization of Surface Groups by ATR- FTIR Spectroscopy}

The surface groups of the membranes were analyzed by attenuated total reflectance Fourier transform infrared spectroscopy (ATR-FTIR) technique, which was performed on a Nicolet FT-IR 360 Spectrometer. The surface of the membranes was in contact with a $\mathrm{ZnSe}$ crystal with a $45^{\circ}$ angle of incidence. Transmittance spectra were obtained in the region of $4000-500 \mathrm{~cm}^{-1}$ with a resolution of $4 \mathrm{~cm}^{-1} .64$ scans were averaged in order to obtain clear transmission spectra for each sample.

\subsubsection{Measurements of Porosity and Pore Size}

Membrane porosity was measured by the method of weighting the dry and wet mass of the membranes. First, the membranes were immersed into distilled water for $24 \mathrm{~h}$ at $20^{\circ} \mathrm{C}$. The membranes were weighed after wiping with filter paper. Then, the wet membranes were placed in an air-circulating oven at $60^{\circ} \mathrm{C}$ for $24 \mathrm{~h}$ for measuring the dry mass. The membrane porosity $(\varepsilon)$ was calculated using the following equation: 
$\varepsilon=\frac{m_{w}-m_{d}}{A L \rho}$

where $m_{w}$ was the mass of wet membrane and $m_{d}$ was the mass of dry membrane. $A, L$, and $\rho$ was the membrane area, the membrane thickness, and water density, respectively.

Mean pore radius $r_{m}(\mu \mathrm{m})$ was determined by filtration velocity method. According to Guerout-ElfordFerry equation, $r_{m}$ could be calculated:

$r_{m}=\sqrt{\frac{(2.9-1.75 \varepsilon) \times 8 \eta L Q}{\varepsilon \times A \times \Delta P}}$

Where $\eta$ was the water viscosity, $L$ was the membrane thickness, $Q$ was the volume of the permeate water per unit time, $A$ was the effective area of the membrane and $\Delta P$ was the operational pressure.

\subsubsection{Measurement of Ultrafiltration Performance}

Ultrafiltration experiment was carried out by using a self made dead-end filtration equipment. The equipment was consisted of a solution reservoir and a membrane filtration cell as shown in Figure 2.

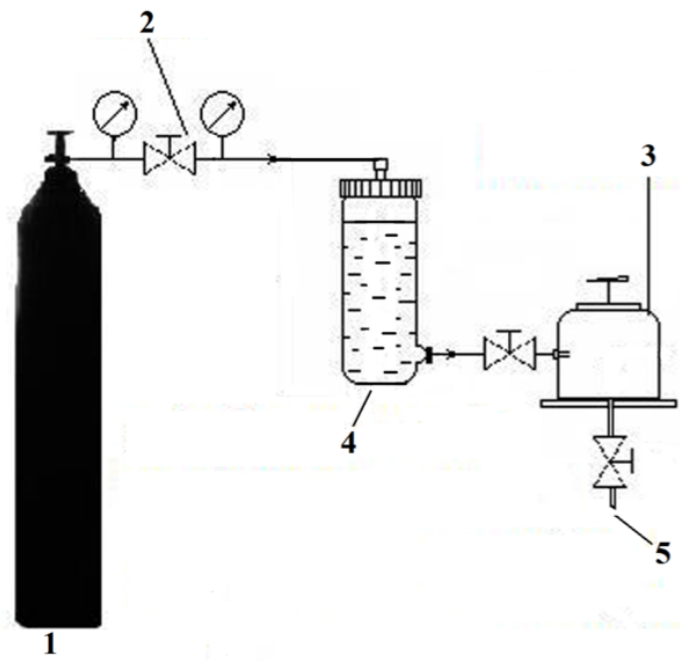

Figure 2: Schematic diagram of UF separation experimental equipment. 1. nitrogen gas, 2. pressure control valve, 3. filtration cell, 4 . solution reservoir, 5. permeat solution.

The membrane effective area was $6.60 \mathrm{~cm}^{2}$. All ultrafiltration experiments were conducted at $25^{\circ} \mathrm{C}$ and the feed pressure was $0.1 \mathrm{MPa}$. The measuring processes were as follows: for the first $30 \mathrm{~min}$, the membranes were compacted at $0.15 \mathrm{MPa}$ to get a steady flux; and then the pure water flux was measured under 0.1 MPa. After this measurement, pure water was changed to $0.1 \mathrm{~g} \cdot \mathrm{L}^{-1}$ BSA solution. At least 5 measurements were collected to obtain an average value. BSA concentration of both the feed and the permeate solutions was measured by UV-VIS spectrophotometer (T6, Beijing Purkinje General Instrument, China) at $280 \mathrm{~nm}$. The BSA permeation flux, $J\left(L \cdot \mathrm{m}^{-2} \cdot \mathrm{h}^{-1}\right)$ was defined with the following equation:

$J=\frac{V}{A \Delta t}$

where $V$ was the volume of permeation, $A$ was the membrane effective area, and $\Delta t$ was the permeation time. Rejection rate $(R)$ was defined with the following equation:

$R=\left(1-\frac{C_{p}}{C_{f}}\right) \times 100$

where $C_{p}$ and $C_{f}$ was the concentration of BSA in the permeation and feed side, respectively.

\subsubsection{Measurement of Protein Adsorption}

To evaluate the fouling resistance of the un-treated membranes and the treated membranes, BSA adsorption experiment was performed through the following procedures. Membrane with an area of 18 $\mathrm{cm}^{2}$ was soaked thoroughly in $0.1 \mathrm{M}$ phosphate buffer solution (PBS) with $\mathrm{pH}$ value of 7.4 for $30 \mathrm{~min}$. BSA solution with the concentration of $1.0 \mathrm{mg} \cdot \mathrm{mL}^{-1}$ was freshly prepared by dissolving BSA into the PBS. The membranes were put into flasks filled with $20 \mathrm{~mL}$ protein solution. These flasks were then incubated in water bath at $25^{\circ} \mathrm{C}$ for $24 \mathrm{~h}$. The concentration of the solution before and after the adsorption was measured and the adsorbed protein amount was calculated. At least three measurements were performed for each sample.

\subsubsection{Measurement of Membrane Potential}

Membrane potential was measured in $\mathrm{KCl}$ solution at room temperature $(\mathrm{pH}=7.0)$. The membranes with area of $10.4 \mathrm{~cm}^{2}$ were pinched with silicone rubber rings between two polyamide half-cells with the volume of $95 \mathrm{~cm}^{3}$. The concentration of $\mathrm{KCl}$ solutions was $1 \times 10^{-3}, 2 \times 10^{-3}, 3 \times 10^{-3}, 4 \times 10^{-3}, 5 \times 10^{-3}, 6 \times 10^{-3}$ and $7 \times 10^{-3}$ $\mathrm{mol} \cdot \mathrm{L}^{-1}$. Each compartment was filled with $88 \mathrm{~mL}$ of $\mathrm{KCl}$ solution, where a peristaltic pump was used at a rate of $65 \mathrm{~mL} \cdot \mathrm{min}^{-1}$ to circulate the solution. During the study, the bottom surface of the membranes was always contacted with the $\mathrm{KCl}$ solution of $1 \times 10^{-3} \mathrm{~mol} \cdot \mathrm{L}^{-1}$. The top surface of the membranes was put in contact with other higher concentration solutions. The electrical 


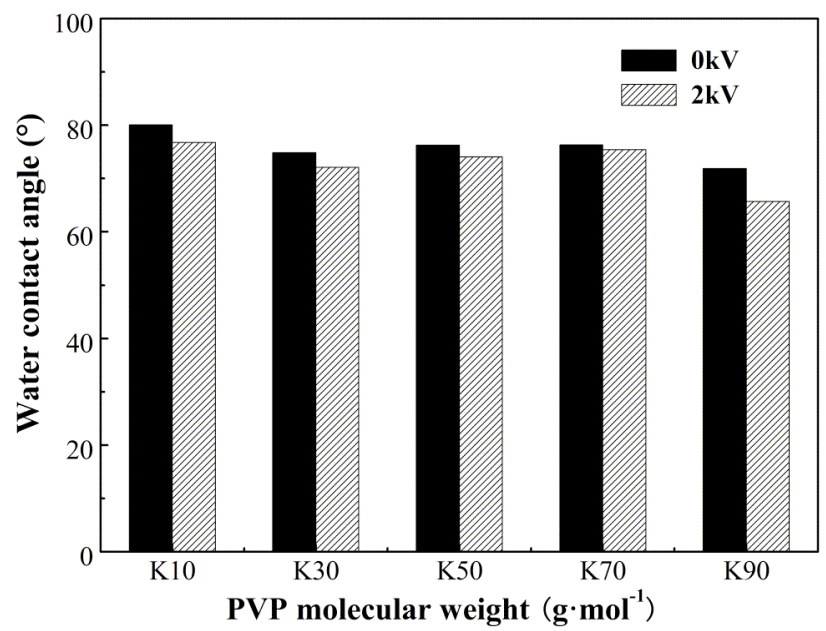

Figure 3: Effect of the external voltage on water contact angle of membranes.

potential difference of the cell $\left(E_{c e l l}\right)$ was measured with two $\mathrm{Ag} / \mathrm{AgCl}$ electrodes which were inserted directly into the two compartments. The membrane potential, $E_{m}(\mathrm{mV})$ was defined as follows:

$E_{m}=E_{\text {cell }}-\frac{R T}{F} \ln \frac{c_{2}}{c_{1}}$

where $R$ is the ideal gas constant, $T$ is the absolute temperature, $F$ is the Faraday constant, $c_{2}$ and $c_{1}$ was the concentration of $\mathrm{Cl}^{-}$ions in bulk solutions $\left(c_{1}>c_{2}\right)$, respectively.

\section{RESULTS AND DISCUSSION}

3.1. Effect of External Voltage on Surface Hydrophilicity, Morphology, Surface Groups, Porosity, Pore Size and Membrane Potential

The change of water contact angle of the membranes with the external voltage and PVP molecular weight is shown in Figure 3. It shows that the water contact angle on all $2 \mathrm{kV}$ membranes was smaller than $0 \mathrm{kV}$ membranes when the same PVP was added although the difference is tiny. In general, the stronger hydrophilicity of the membranes possessed, the stronger anti-fouling ability would exist $[13,14]$.

Figure 4 shows the cross-sectional SEM image of two PVDF membranes which were prepared at the conditions of $0 \mathrm{kV}$ and $2 \mathrm{kV}$ external voltages, respectively. It can be seen that all the membranes exhibit typical asymmetric cross sectional structure, consisting of a skin layer as a selective barrier and a much thicker finger-like sub-structure. However, there are no clear differences between the sublayers of the two membranes when the same kind of PVP was used.

The SEM image of the top surface morphology of the two membranes is shown in Figure $\mathbf{5}$. It seems that the surface of the electric treated membrane has somewhat smoother appearance than the un-treated membrane when the same kind of PVP was used. Therefore, the external voltage induced the changes in permeation property may result from the change in the surface skin layer morphology. This is verified further by the permeation experimental results in Figure 13.

The chemical structures of the electric treated and un-treated membranes were characterized by ATRFTIR. Figure 6 presents the ATR-FTIR spectra for the membranes when PVP $\mathrm{K} 70$ as used as additive. It shows that there is no significant difference in the main transmittance peaks. Therefore, the functional groups in the surface of the two membranes were almost same. The results confirmed that the external voltage had no influence on the chemical groups in the membrane surface.
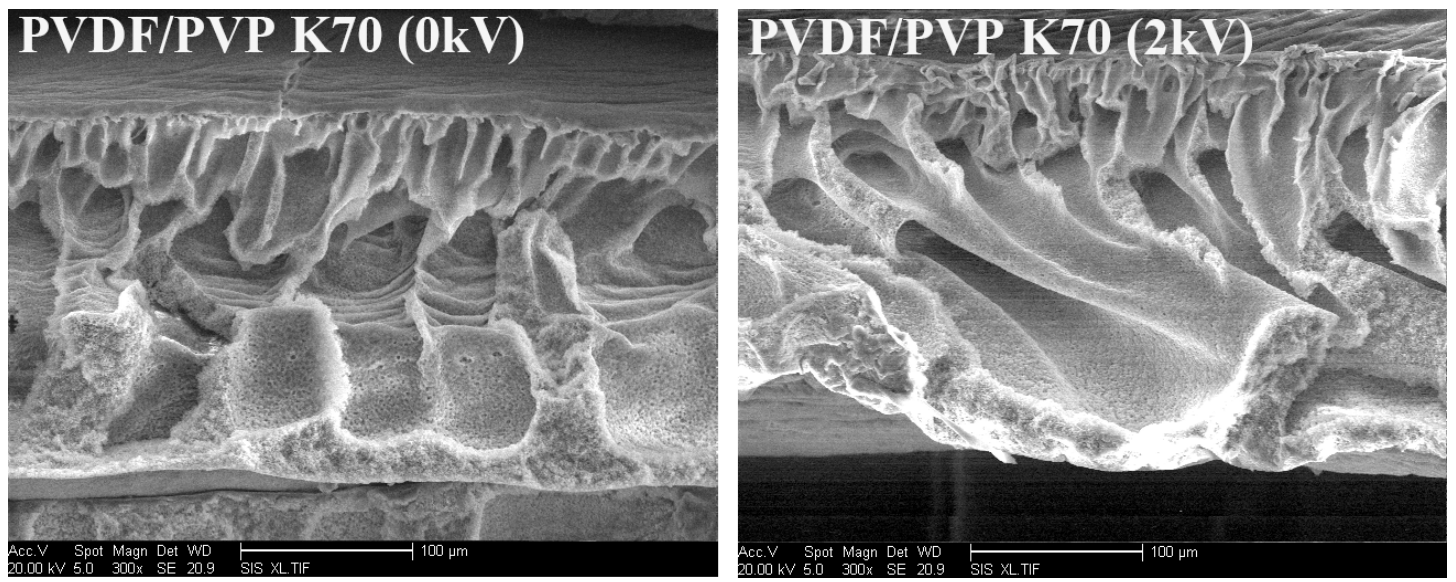

Figure 4: Cross section morphology of membranes with PVP K70 as additive. 

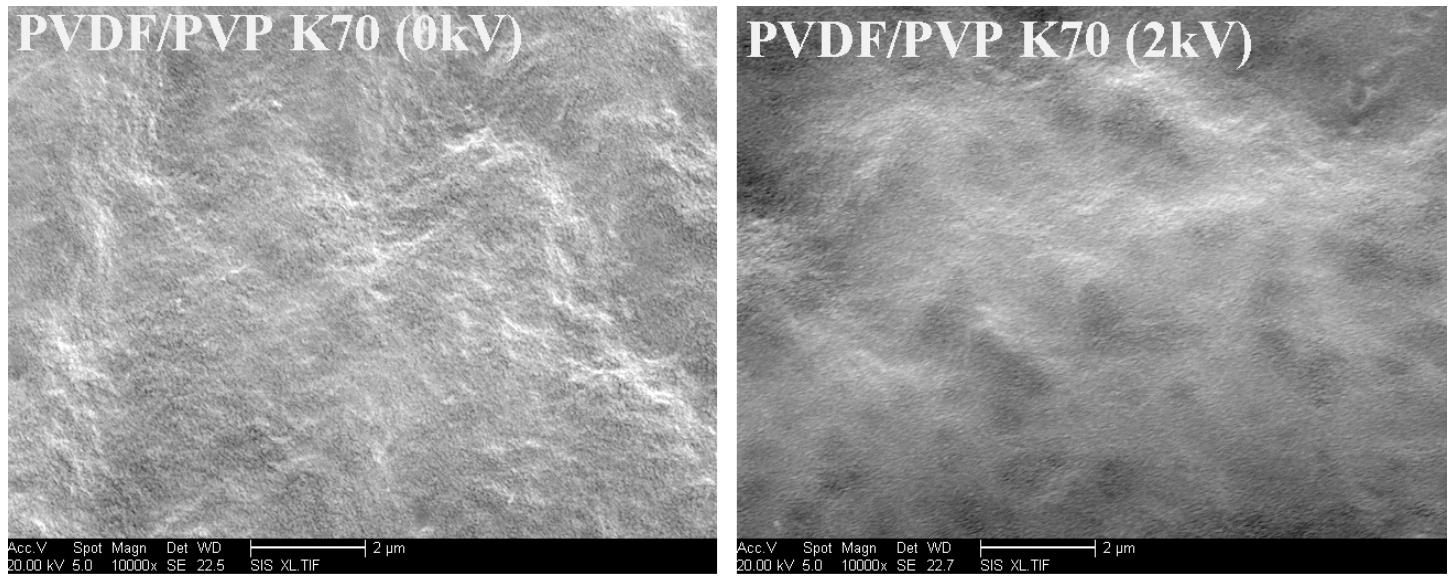

Figure 5: Top surface morphology of membranes with PVP K70 as additive.

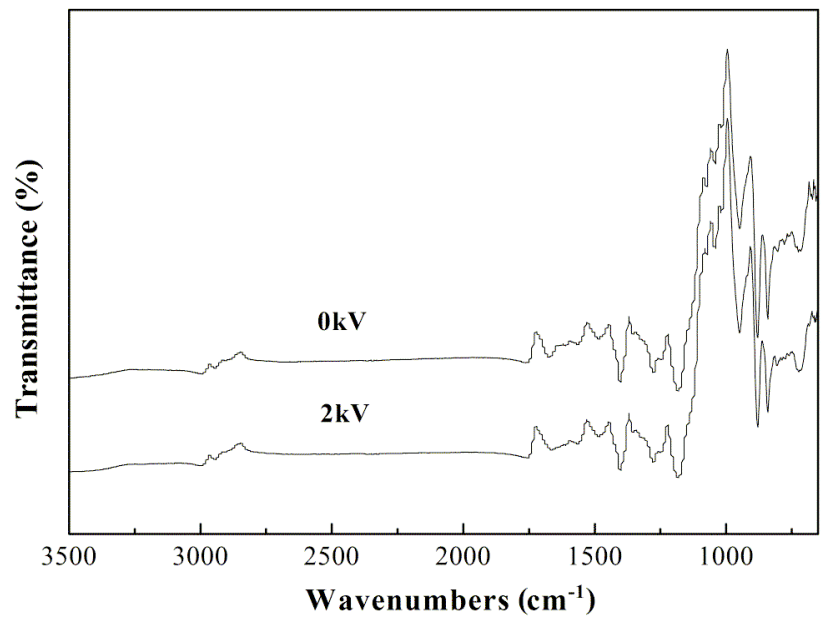

Figure 6: ATR-FTIR spectra of top surface of membranes with PVP 70 as additive.

Figure 7 shows the porosity of the membranes. The porosity results revealed that the membrane porosity increased with the increase of the molecular weight of PVP and reached the maximum when PVP K70 was added. Then it decreased with the molecular weight of

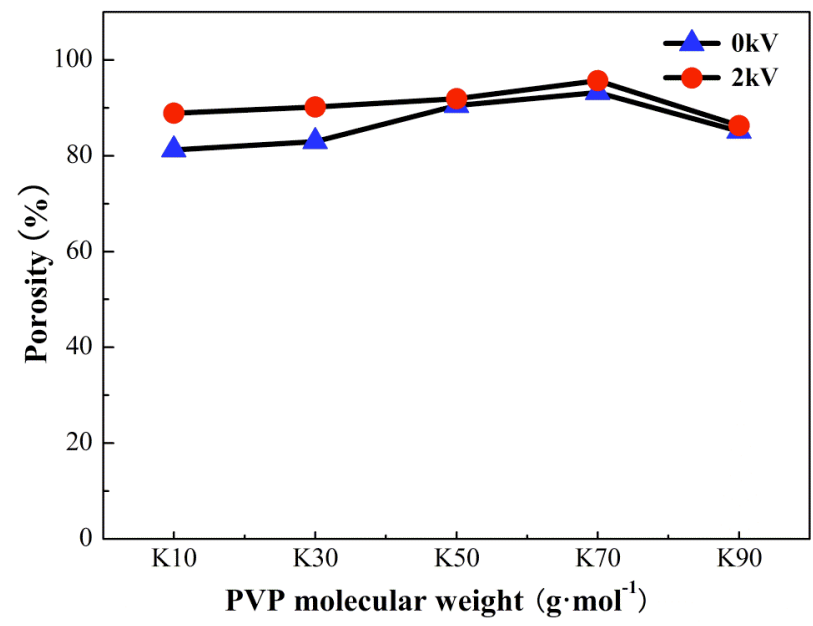

Figure 7: Porosity of PVDF membranes.
PVP as the molecular weight further increased. Increase in the porosity would lead to the increase in the permeate flux of the membranes.

The mean pore size of the membranes were shown in Figure 8. The membrane mean pore size was in the range $3.29 \mathrm{~nm}-4.27 \mathrm{~nm}$. The mean pore size of membranes were decreased with increase in molecular weight of PVP. This can be attributed to the difference in diffusion rates of different molecular weight of PVP. Smaller molecular weight additives having comparatively higher diffusivity can diffuse out during immersion along with the solvent. On the contrary, the diffusion rates of higher molecular weight additives (PVP K90) are much lower, they take more time to reach the surface. This will give sufficient time for the polymer molecules to aggregate on top of the membrane and form a denser top layer with relatively smaller size pores.

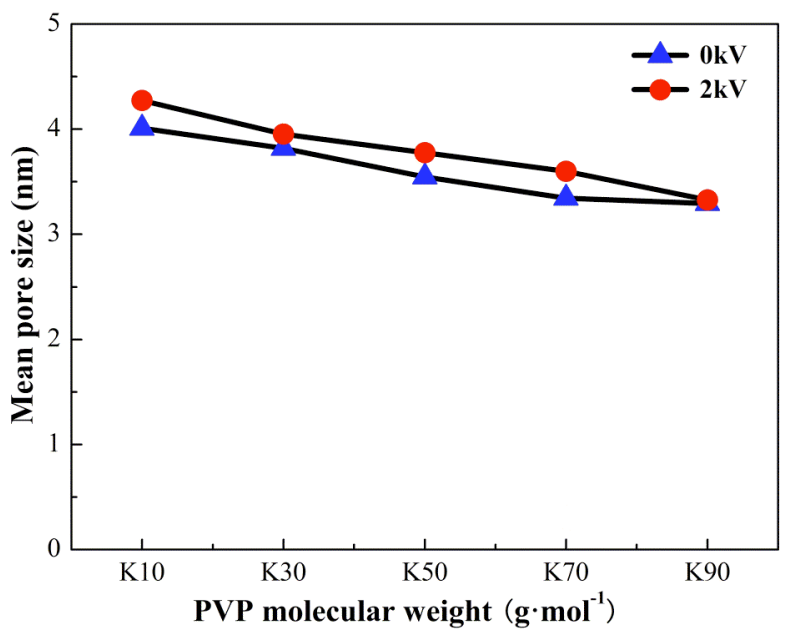

Figure 8: Mean pore size of PVDF membranes.

Figure 9 shows the effect of the external voltage on the membrane potential. It presents that when 
increasing the PVP molecular weight, the membrane potential decreased for both of the membranes prepared under $0 \mathrm{kV}$ and $2 \mathrm{kV}$, respectively. When PVP with the same molecular weight was added, the membrane potential of $2 \mathrm{kV}$ membrane was lower than the $0 \mathrm{kV}$ membrane. Furthermore, all the membrane potential of the $2 \mathrm{kV}$ membranes was negative as shown in Figure 9. The negative membrane potential meant that negative charges existed at the top surface of the $2 \mathrm{kV}$ membranes. Because a positive electric field was formed during the preparation of the membranes, negative charges would be permanently held at the top surface of the prepared membranes.

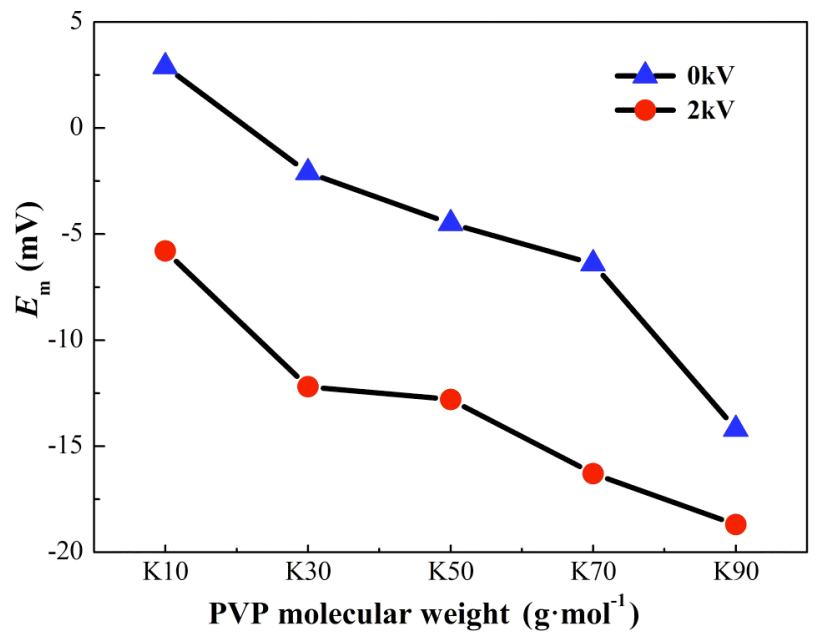

Figure 9: Membrane potential of membranes.

\subsection{Effect of PVP Molecular Weight on BSA Adsorption Amount}

The effects of PVP molecular weight and external voltage on the surface protein adsorption of the membranes are shown in Figure 10. It is obvious that the surface protein adsorption amount decreased linearly with the increasing of PVP molecular weight. The external voltage had large influence on the surface protein adsorption. All the external voltage treated membranes exhibited lower protein adsorption amount than the un-treated membranes when the same PVP was added. The protein adsorption amount of all the treated membranes was decreased by 65-78 \%. Especially for the membrane with PVP K90 as additive, the adsorption amount decreased $78 \%$, reaching $15.66 \mu \mathrm{g} \cdot \mathrm{cm}^{-2}$.

Figure 11 shows the effect of membrane potential on the protein adsorption. It presents that the adsorbed BSA amounts increased when the membrane potential increased. The isoelectric point (IEP) of BSA appears when the $\mathrm{pH}$ value is 4.8 , and BSA molecules show

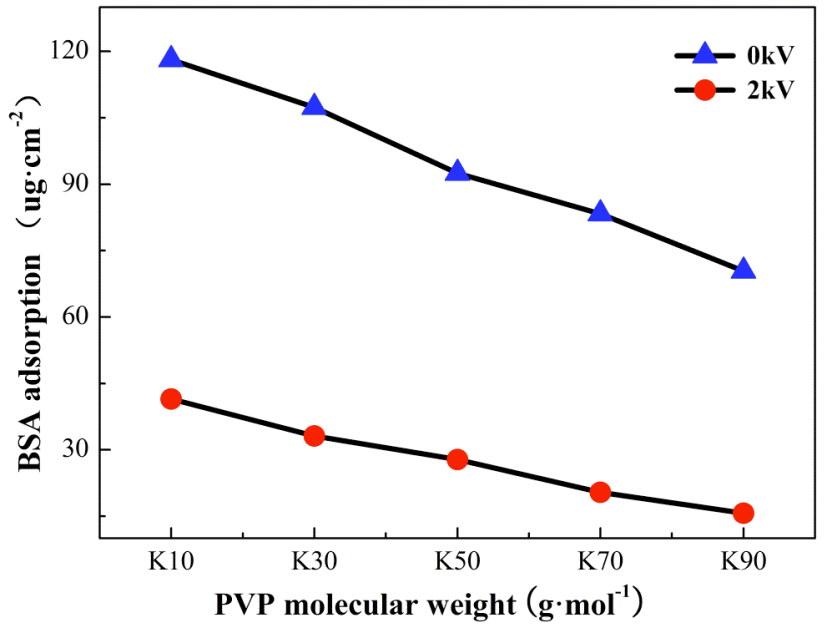

Figure 10: BSA adsorption amount on membranes.

negative potential when the $\mathrm{pH}$ value is higher than 4.8 [15]. Therefore, in this study, the BSA adsorption amounts decreased with the decrease of the membrane potential because a negative-negative electrostatic repulsive force existed between the surface of the membranes and BSA molecules. However, the BSA adsorption amount on the $0 \mathrm{kV}$ and $2 \mathrm{kV}$ membranes showed very different at the same membrane potential. Thus, BSA adsorption clearly didn't depend on just the membrane potential. Some other effects may also have big influence on the BSA adsorption, such as the morphology of the surface pore, which needs further research works to explain it.

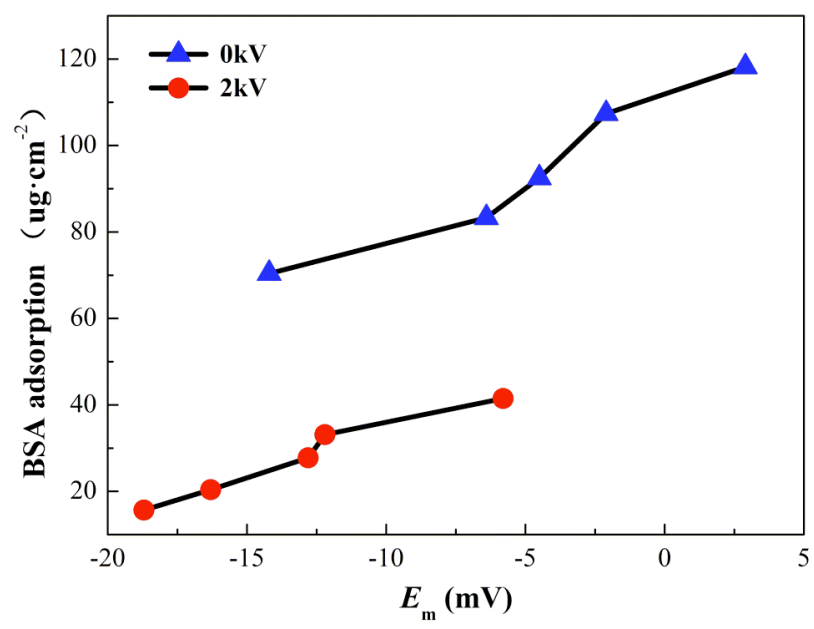

Figure 11: Effect of membrane potential on BSA adsorption amount.

\subsection{Effect of PVP Molecular Weight on Permeation Property}

Figure 12 shows the BSA solution flux. This trend was in agreement with the obtained porosity change of the membranes in Figure 7. When increasing the PVP 
molecular weight, the BSA solution flux of the membranes first increased and then decreased. When PVP K70 was added, the BSA solution flux reached the maximum values of $35.27 \mathrm{~L} \cdot \mathrm{m}^{-2} \cdot \mathrm{h}^{-1}$ and $47.18 \mathrm{~L} \cdot \mathrm{m}^{-2} \cdot \mathrm{h}^{-1}$ for the membranes prepared under $0 \mathrm{kV}$ and $2 \mathrm{kV}$, respectively.

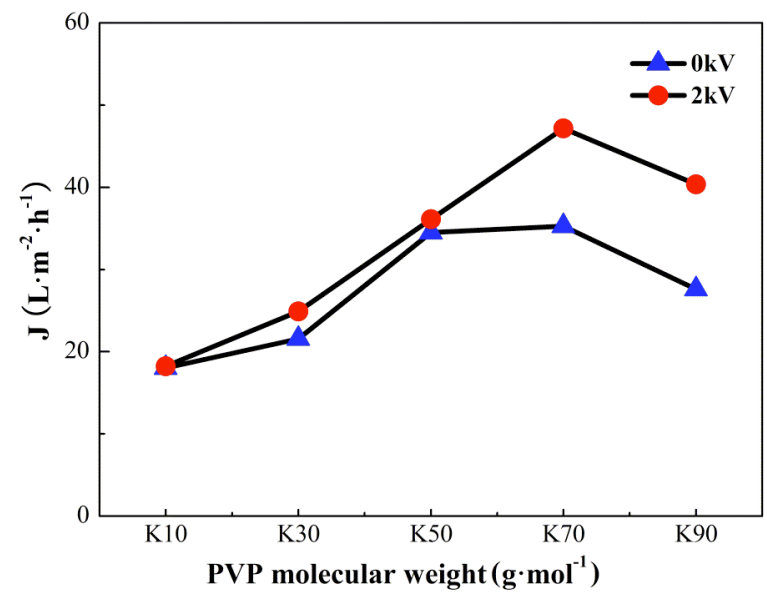

Figure 12: BSA solution flux of membranes with different PVP as additive.

The $J \times R / 100$ value for the membranes was also calculated and the trend curves were given in Figure 13. As increasing the PVP molecular weight, $J \times R / 100$ value for the membranes increased firstly and then decreased. When PVP K70 was added, the $J \times R / 100$ reached the maximum values of 12.18 and 15.76 for the membranes prepared under $0 \mathrm{kV}$ and $2 \mathrm{kV}$, respectively. The shape of the curves was similar to the curves shown in Figure 12.

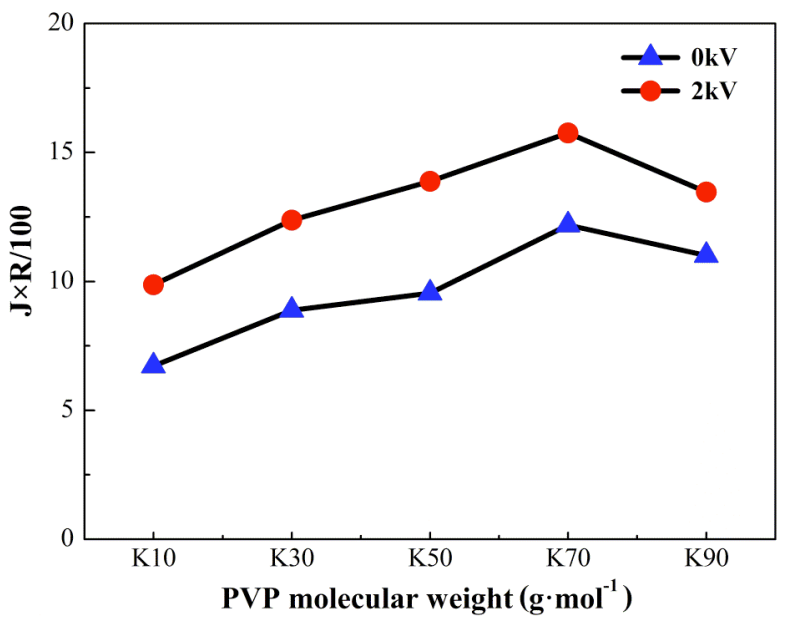

Figure 13: Permeation properties of membranes with different PVP as additive.

\section{CONCLUSION}

PVDF UF membranes were prepared under the external electric field of $2 \mathrm{kV}$ with PVP as additive by the phase inversion method. The water contact angle of the treated membranes decreased and the hydrophilicity of these membranes was slightly improved. The SEM images showed that the surface of the electric treated membrane has somewhat smoother appearance than the un-treated membrane when the same kind of PVP was used. However, there are no clear differences between the sublayers of the two membranes. The separation performance of the external electric field treated membrane was also superior to that of the un-treated membrane. Meantime, the BSA protein adsorption experiment results showed that the anti-fouling ability of the external electric field treated membranes was distinctly enhanced when comparing with the un-treated membranes due to more negative charges were fixed on the surface of the treated membranes by the external electric field. For the external voltage treated membranes, the BSA adsorption amount decreased by 65-78 \%. In a word, the external voltage treated method can be used as a suitable candidate for the improvement of membrane antifouling performance under proper conditions.

\section{ACKNOWLEDGEMENT}

The authors would like to acknowledge the financial support by National Natural Science Foundation of China (21376048).

\section{REFERENCES}

[1] Judd S, Judd C, Eds. The MBR Book: Principles and Applications of Membrane Bioreactors in Water and Wastewater Treatment. Great Britain: Elsevier 2006.

[2] Wang Q, Wang Z, Wu Z. Effects of solvent compositions on physicochemical properties and anti-fouling ability of PVDF microfiltration membranes for wastewater treatment. Desalination 2012; 297: 79-86.

\section{http://dx.doi.org/10.1016/j.desal.2012.04.020}

[3] Feng C, Khulbe KC, Matsuura T, et al. Production of drinking water from saline water by air-gap membrane distillation using polyvinylidene fluoride nanofiber membrane. J Membr Sci 2008; 311: 1-6. http://dx.doi.org/10.1016/j.memsci.2007.12.026

[4] Liu F, Awanis Hashim N, Liu Y, Moghareh Abed MR, Li K. Progress in the production and modification of PVDF membranes. J Membr Sci 2011; 375: 1-27.

http://dx.doi.org/10.1016/j.memsci.2011.03.014

[5] Liu X, Peng Y, Ji S. A new method to prepare organicinorganic hybrid membranes. Desalination 2008; 221: 37682.

http://dx.doi.org/10.1016/j.desal.2007.02.056

[6] Meng J, Chen C, Huang L, Du Q, Zhang Y. Surface modification of PVDF membrane via AGET ATRP directly from the membrane surface. Appl Surf Sci 2011; 257: 628290 .

http://dx.doi.org/10.1016/j.apsusc.2011.02.062

[7] Wang P, Tan KL, Kang ET, Neoh KG. Plasma-induced immobilization of poly(ethylene glycol) onto poly(vinylidene 
fluoride) microporous membrane. J Membr Sci 2002; 195: 103-14.

http://dx.doi.org/10.1016/S0376-7388(01)00548-8

[8] Dong $\mathrm{C}, \mathrm{He} \mathrm{G}, \mathrm{Li} \mathrm{H}$, et al. Antifouling enhancement of poly(vinylidene fluoride) microfiltration membrane by adding $\mathrm{Mg}(\mathrm{OH})_{2}$ nanoparticles. J Membr Sci 2012; 387-388: 40-47. http://dx.doi.org/10.1016/j.memsci.2011.10.007

[9] Zhao $\mathrm{Y}$, Qian $\mathrm{Y}$, Zhu B, Xu Y. Modification of porous poly(vinylidene fluoride) membrane using amphiphilic polymers with different structures in phase inversion process. J Membr Sci 2008; 310: 567-76. http://dx.doi.org/10.1016/j.memsci.2007.11.040

[10] Hester JF, Banerjee P, Won YY, et al. ATRP of amphiphilic graft copolymers based on PVDF and their use as membrane additives. Macromolecules 2002; 35: 7652-61. http://dx.doi.org/10.1021/ma0122270

[11] Ying L, Yu WH, Kang ET, Neoh KG. Functional and surfaceactive membranes from poly(vinylidene fluoride)-graftpoly(acrylic acid) prepared via RAFT-mediated graft copolymerization. Langmuir 2004; 20: 6032-40. http://dx.doi.org/10.1021/la049383v
[12] Wang Y, Zhang X, Shi B, Jia L, Zhou X. Preparation of AntiFouling Polyethersulfone Ultrafiltration Membrane by an External High Voltage Electric Enhancing Method. Sep Sci Technol 2010; 45: 2380-86.

http://dx.doi.org/10.1080/01496395.2010.488259

[13] Bourne H, Eastmond GC, Gibas M, Pacynko WF, Paprotny J. Grafted and segmented hydrophilic polyimides for microfiltration membranes II. Fouling measurements. J Membr Sci 2002; 207: 17-27.

http://dx.doi.org/10.1016/S0376-7388(01)00749-9

[14] Zhao Y, Wee K, Bai R. Highly hydrophilic and low-proteinfouling polypropylene membrane prepared by surface modification with sulfobetaine-based zwitterionic polymer through a combined surface polymerization method. J Membr Sci 2010; 362: 326-33. http://dx.doi.org/10.1016/j.memsci.2010.06.037

[15] Saxena A, Shahi VK. PH controlled selective transport of proteins through charged ultrafilter membranes under coupled driving forces: An efficient process for protein separation. J Membr Sci 2007; 299: 211-21. http://dx.doi.org/10.1016/j.memsci.2007.04.043 